\title{
Review of the Imaging Features of Benign Osteoporotic and Malignant Vertebral Compression Fractures
}

\author{
(D).T. Mauch, (D) C.M. Carr, (1) H. Cloft, and IDF.E. Diehn
}

\begin{abstract}
SUMMARY: Vertebral compression fractures are very common, especially in the elderly. Benign osteoporotic and malignant vertebral compression fractures have extremely different management and prognostic implications. Although there is an overlap in appearances, characteristic imaging features can aid in the distinction between these 2 types of compression fractures. The aim of this review is to characterize the imaging features of benign and malignant vertebral compression fractures seen with CT, PET, SPECT, and MR imaging.
\end{abstract}

ABBREVIATIONS: $\mathrm{SI}=$ signal intensity; SUV = standard uptake value; VCF = vertebral compression fracture

$V^{e}$ ertebral compression fractures (VCFs) can have a variety of etiologies, including trauma, osteoporosis, or neoplastic infiltration. Osteoporotic VCFs have a prevalence of approximately $25 \%$ among all postmenopausal women and occur less frequently in similarly aged men. ${ }^{1}$ Trauma is the most common etiology in those younger than 50 years of age. However, many cancers, such as breast, prostate, thyroid, and lung, have a propensity to metastasize to bone, which can lead to malignant VCFs. ${ }^{2}$ Indeed, the spine is a site of metastasis in $10 \%-15 \%$ of cancers. ${ }^{3}$ In addition, primary tumors of bone and lymphoproliferative diseases such as lymphoma and multiple myeloma can be the cause of malignant VCFs. Differentiating benign and malignant VCFs can present a diagnostic dilemma, particularly in the elderly, with considerable management and prognostic implications. Advanced imaging is often used to attempt to distinguish benign from malignant VCFs.

The aim of this review is to describe and illustrate the imaging features of benign and malignant VCFs. The imaging modalities used in the clinical setting for this diagnostic purpose include CT, PET, SPECT, and MR imaging. MR imaging traditionally has been the technique of choice because characteristic morphologic features, enhancement patterns, and signal intensities are well-described in the literature. Relatively recently, chemical shift, dynamic contrast-enhanced imaging, and diffusion-weighted MR imaging have also been more thoroughly investigated. The multimodality imaging features and common pitfalls will be discussed.

From the Department of Radiology, Mayo Clinic, Rochester, Minnesota.

Please address correspondence to Justin Mauch, MD, Department of Radiology, Mayo Clinic, 200 First St SW, Rochester, MN 55905; e-mail: Mauch.Justin@Mayo.edu

- Indicates open access to non-subscribers at www.ajnr.org

http://dx.doi.org/10.3174/ajnr.A5528

\section{Pitfalls}

In the subsequent sections, technique and sign-related pitfalls will be discussed. In general, most pitfalls can be attributed to a few common issues: The first is that acute ( $<2$ weeks) and subacute ( 2 weeks to 3 months) benign VCFs often have large areas of MR signal alteration or increased metabolism on nuclear medicine modalities that can mimic malignancy, owing to intertrabecular hemorrhage, edema, and the early reparative process. ${ }^{4,5}$ Chronic (>3 months) benign VCFs have small areas of usually linear signal alteration and restoration of fatty marrow and normal metabolism, which make these easier to identify. ${ }^{4}$ Unfortunately, precise timing of the fracture can often be difficult to elicit from the patient or medical records.

Multiple myeloma, a common cause of VCFs, is also an important pitfall. Myelomatous lesions can be present within vertebral bodies with normal bone marrow signal. ${ }^{6}$ Multiple myeloma infiltrates bone marrow either diffusely or in a nodular pattern. When it is diffusely distributed in the bone marrow, it may give the appearance of osteoporosis, potentially from diffuse osteoclast activation. ${ }^{6,7}$ VCFs from multiple myeloma can appear benign in $38 \%$ of cases. $^{7}$ Acute-subacute symptomatic myelomarelated VCFs may not demonstrate edema, either. ${ }^{8}$ Inadvertent inclusion or exclusion of this patient population in studies may account for the sometimes discordant findings in the literature.

A summary of the key imaging features that can be helpful in differentiating benign and malignant fractures is found in the Table.

\section{MR Imaging}

Morphologic Features. According to the literature, abnormal marrow signal involving the pedicles or other posterior elements 


\begin{tabular}{|c|c|c|}
\hline Modality & Benign VCF Features & Malignant VCF Features \\
\hline MRI: morphology & $\begin{array}{l}\text { Normal posterior element signal, }{ }^{20} \text { retropulsed } \\
\text { bone fragments, }, 12,14,17 \text { additional benign } \\
\text { VCFs }^{18,19}\end{array}$ & $\begin{array}{l}\text { Abnormal posterior element signal, }{ }^{9-19} \text { epidural or } \\
\text { paravertebral soft-tissue mass, }, 10,12-15,17-19 \\
\text { expanded posterior vertebral contour, } \\
\text { metastasis in other vertebrae }{ }^{9,14,18}\end{array}$ \\
\hline $\begin{array}{l}\text { MRI: signal and enhancement } \\
\text { patterns }\end{array}$ & $\begin{array}{l}\text { Preserved normal marrow signal, }{ }^{9-12,14,15,17} \text { regular } \\
\text { margins, }{ }^{13,17,28} \text { linear horizontal hypointense } \\
\text { T1/T2 band, }{ }^{4,9,11,14,18} \text { fluid sign, }{ }^{9,18,19,26} \text { normal } \\
\text { enhancement relative to adjacent vertebrae } \\
\text { and at } 3 \text { mo }^{12,13,15,28}\end{array}$ & $\begin{array}{l}\text { Geographic replacement of normal marrow } \\
\text { signal, }{ }^{11,12,14-18,24,28} \text { irregular margins, } \\
\text { increased enhancement relative to adjacent } \\
\text { vertebrae and at } 3 \mathrm{mo}^{12,13,15,28}\end{array}$ \\
\hline MRI: diffusion & No restricted diffusion ${ }^{18,27,30,32-45}$ & Increased restricted diffusion ${ }^{18,27,30,32-45}$ \\
\hline MRI: chemical shift & Loss of SI on opposed-phase $\mathrm{in}^{18,51-53}$ & $\begin{array}{l}\text { No change or slight loss of SI on } \\
\text { opposed-phase, }{ }^{18,51-53} \text { ratio of } \\
\text { opposed-phase to in-phase } \mathrm{SI}>0.8-1.0^{18,51-53}\end{array}$ \\
\hline CT & $\begin{array}{l}\text { Retropulsed bone, },^{54,55} \text { puzzle sign, }{ }^{10,54,55} \text { sharp } \\
\text { fracture lines, }{ }^{10,54,55} \text { intravertebral vacuum } \\
\text { phenomenenon }\end{array}$ & $\begin{array}{l}\text { Bone destruction, },{ }^{10,54,55} \text { epidural or focal } \\
\text { paravertebral soft tissue mass }{ }^{54,55}\end{array}$ \\
\hline PET & SUV 2 SDs below liver SUV $57-60$ & SUV of $>3-4.7$ or 2 SDs above liver SUV $57-60$ \\
\hline SPECT & Vertebral body and/or facet joint uptake ${ }^{63}$ & $\begin{array}{l}\text { Vertebral body with pedicle and/or spinous } \\
\text { process uptake, }{ }^{63} \text { marginal uptake in cold lesion }{ }^{63}\end{array}$ \\
\hline
\end{tabular}

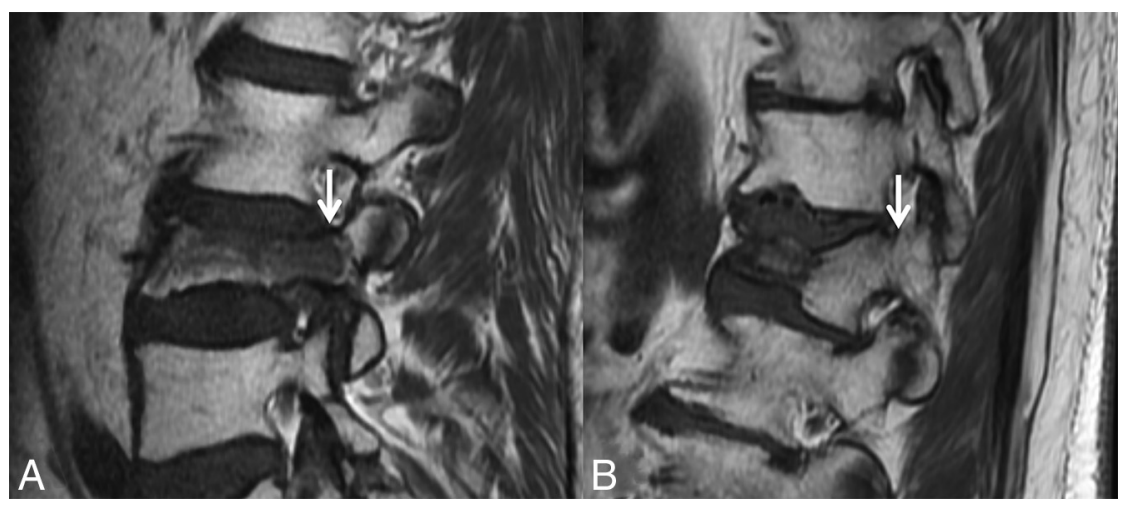

FIG 1. Abnormal pedicle marrow signal in a malignant VCF. A, Sagittal TIWI of the lumbar spine demonstrates a malignant VCF of L3 with loss of the high T1 normal marrow signal within the pedicle (arrow), indicating tumor infiltration. B, Sagittal TIWI of the lumbar spine demonstrates a typical benign VCF of Ll anteriorly, with preservation of the normal high $\mathrm{Tl}$ marrow signal within the pedicle (arrow).

is a strong indicator of malignancy in VCFs. ${ }^{9-19}$ Tumor spread to the posterior elements typically occurs before tumor-associated structural instability leads to fracture within the vertebral body (Fig 1A). In contradistinction, according to the literature, osteoporotic fractures infrequently have signal change in the posterior elements (Fig 1B). ${ }^{20}$ However, in our experience, as has been shown in the literature, osteoporotic fractures commonly cause such posterior element signal abnormalities. ${ }^{21}$ Possible reasons include inflammation related to biomechanical stress and/or direct injury. $^{22}$

Moreover, malignant VCFs may have preserved marrow signal within 1 or both pedicles (for example, preserved signal on the right in Fig 2) because the presence of abnormal signal is dependent on tumor infiltration.

The presence of abnormal epidural or paravertebral soft-tissue signal/enhancement is another finding suggesting a pathologic VCF. ${ }^{9,10,12-15,17-19}$ When this is present, it represents direct extension of tumor from the vertebrae into the epidural or paravertebral space (Figs 3-5). This can occur without fracture or retropulsion. The morphology of this epidural or paravertebral infiltration tends to be masslike. A bilobed appearance in the ven- tral extradural space is more commonly seen in neoplastic disease, as opposed to non-neoplastic disease, in which there is preservation of the strong attachment of the central septum. ${ }^{23}$ A potential pitfall in benign VCFs is when there is paravertebral or epidural hemorrhage with associated edema that mimics a soft-tissue mass. Except for acute posttraumatic fractures, the paravertebral hemorrhage and edema tend to be ill-defined, smooth, and/or rim-shaped about the vertebral body, as opposed to the appearance of a soft-tissue mass, which is seen with malignant VCFs. However, malignant VCFs may also demonstrate smooth and rim-shaped signal abnormality/enhancement about the vertebral body if peritumoral inflammation is present and/or there is no tumor infiltration of the cortex of the vertebral body. ${ }^{13}$

A convex vertebral contour, specifically expansion of the posterior aspect of the vertebral contour, is an imaging feature strongly suggestive of malignant fracture. ${ }^{9,11,12,14,18,24}$ Because tumor infiltrates and destroys the cortex, an axial load causes bulging of the mass into the ventral epidural space. The bulge extends beyond the normal posterior margin of the vertebral body, resulting in a convexity, rather than the normal anatomic concavity of the vertebral body (Figs $3 A$, 4, and 5). Uncommonly, a similar finding can sometimes be seen in benign VCFs, primarily in the acute posttraumatic setting, ${ }^{15,17}$ in which a ventral epidural hematoma can contribute to this appearance. ${ }^{15,17}$

Retropulsion of bone fragments from the posterior aspect of the vertebral body, rather than an expansile, convex contour, is characteristic of benign VCFs (Fig 6). ${ }^{9,12,14,17}$ This is typical with axial loading from traumatic compression fractures, especially burst-type fractures. ${ }^{20}$

The location of a VCF within the spinal column has been reported to indicate the likelihood of benignity or malig- 
nancy, ${ }^{11,14,17-19,25}$ but this feature is of limited clinical utility. According to one study, thoracic and lumbar spine traumatic fractures were much more likely to be malignant than those occurring in the cervical spine. ${ }^{25}$ In another study, lumbar fractures were more frequently malignant than thoracic fractures. ${ }^{11}$

Multiple VCFs throughout the spine typically favor a benign osteoporotic etiology. However, the possibility of underlying multiple myeloma should be considered in these patients ${ }^{14}$; multifocal metastases with multilevel pathologic fractures are less likely to cause this appearance. The presence of other healed be-

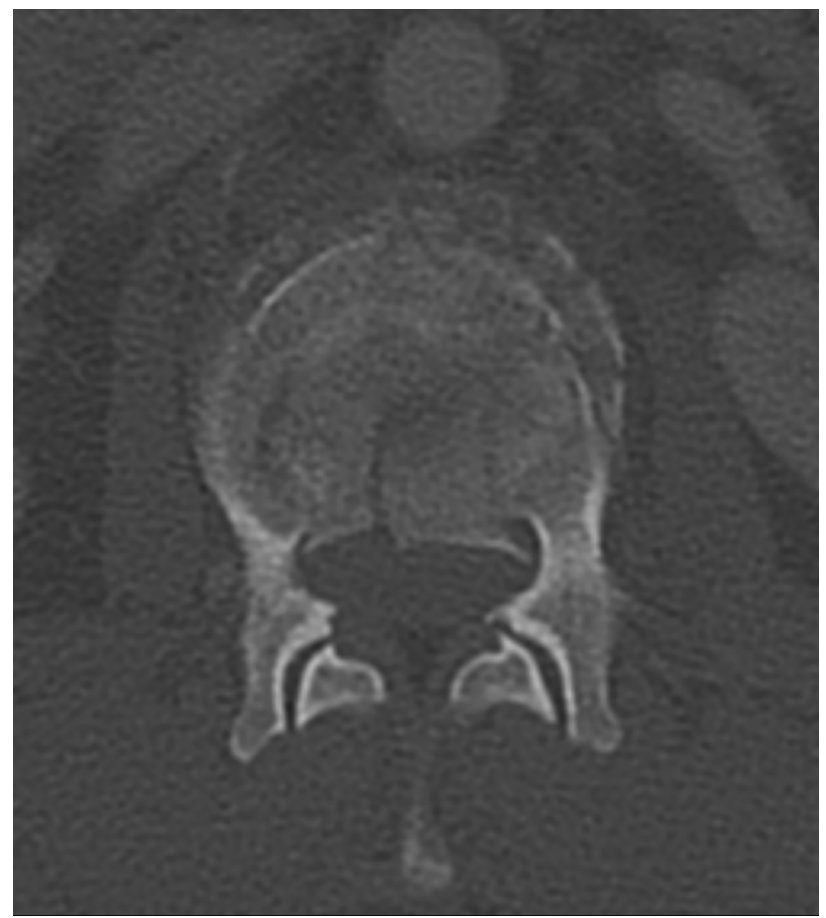

FIG 2. Fracture lines without cortical destruction in a benign VCF. Axial CT with bone windows shows the linear and well-delineated borders of the slightly displaced bone fragments within this benign VCF, an example of the puzzle sign.

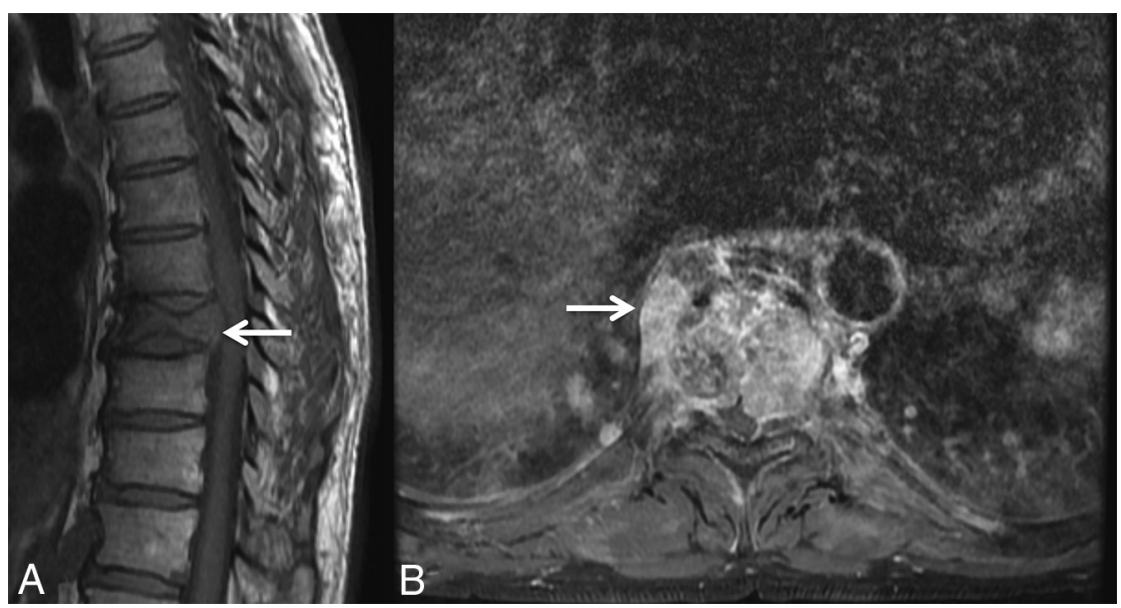

FIG 3. Masslike extension into the paravertebral and epidural space in a malignant VCF. A, Sagittal TIWI of the thoracic spine demonstrates a malignant VCF of T9 with loss of the high T1 normal marrow signal within the vertebral body and convex bowing of the posterior cortex (arrow), both signs indicating a malignant fracture. $B$, Axial postcontrast T1WI with fat saturation of the T9 fracture demonstrates an irregular enhancing mass (arrow) extending into the right paraspinal soft tissues and the epidural space in this malignant VCF. nign VCFs or compression deformities without bone marrow edema suggests benignity of a new fracture. ${ }^{18,19}$ Likewise, known spinal metastasis within other segments or indeterminate vertebral lesions suggest malignancy as the cause of new fractures. ${ }^{9,14,18}$ A potential pitfall would be that it is possible to have both malignant and benign VCFs in the same patient.

Signal Intensity and Enhancement Patterns. An established strength of MR imaging lies in its ability to evaluate bone marrow. Both T1- and T2-weighted imaging have characteristic signal intensity patterns that can be used to discern a pathologic entity and differentiate benign and malignant VCFs. ${ }^{10-18,24,26-28}$ The distinguishing signal intensities arise from 2 different mechanisms of fracture. In malignant VCFs, tumor infiltrates throughout the bone marrow and eventually the trabeculae and cortex, leading to a fracture. ${ }^{17}$ Malignant or metastatic VCFs often have total replacement of the normally high $\mathrm{T} 1$ bone marrow signal intensity (SI), resulting in diffuse homogeneous low SI. ${ }^{11,12,14-18,24,28}$ This was present in up to $88 \%$ of metastatic lesions in 1 series. ${ }^{17}$ Meanwhile, in osteoporosis, the underlying mechanism leading to fracture is the loss of bone mineral density with preservation of the bone marrow. ${ }^{17}$ Therefore, areas of preserved normal high $\mathrm{T} 1$ and intermediate T2 SI within the bone marrow of a collapsed vertebral body are more often found in benign VCFs. ${ }^{9-12,14,15,17} \mathrm{Un}$ fortunately, some VCFs with areas of spared normal bone marrow signal will also be malignant. Likewise, benign VCFs can also have abnormalities in bone marrow signal characteristics due to edema, which can demonstrate diffuse hypointensity on T1WI and patchy enhancement. ${ }^{4,14,16}$

Characterization of the margin between spared normal bone marrow signal and abnormal signal within the collapsed vertebrae can be a key to indicating the cause of the fracture. Ill-defined, irregular, or infiltrative margins are more likely to be found in malignant VCFs, while well-defined or regular margins are typical in benign VCFs. ${ }^{13,17,28}$

As an example of well-defined margins, a sign of benignity is a linear horizontal band of low T1 and T2 signal, often adjacent to the endplate (Fig 7). ${ }^{4,9,11,14,18}$ The finding often correlates to a fracture line or area of cancellous bone compaction, which can sometimes be seen on CT. ${ }^{12}$

A "fluid sign" refers to a focal, linear, or triangular area of T2 hyperintensity, best seen with fat-suppressed T2-weighted images, which can be present in acute, subacute, and chronic fractures. ${ }^{29}$ This linear T2 hyperintensity occurs in a background of diffuse hyperintensity (edema) in the vertebral body (Fig 8). ${ }^{26}$ It is thought to develop when fluid from bone marrow edema collects in an area of ischemic osteonecrosis after an acute fracture. ${ }^{26}$ Sometimes a benign fracture/ cleft may be filled with gas instead of or in addition to fluid; this can be recognized on MR imaging as strikingly hypointense signal on T1WI and T2WI, though this is generally more easily de- 


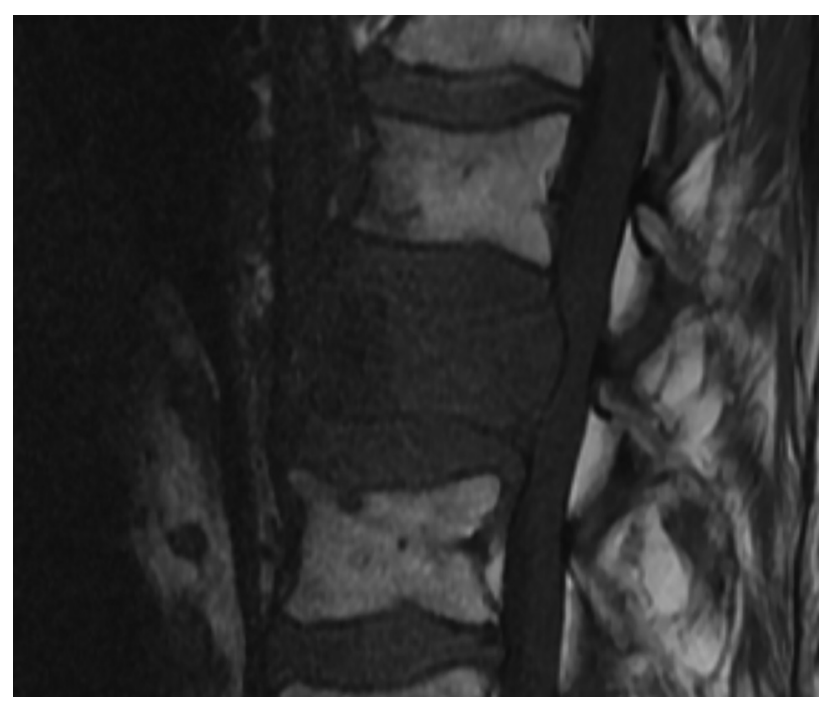

FIG 4. Diffuse abnormal marrow signal in a malignant VCF. Sagittal TIWI of the lumbar spine demonstrates a malignant VCF of L2 with marked complete replacement of the normal high $\Pi$ vertebral body marrow signal. The diffuse $\mathrm{T} 1$ hypointensity indicates tumor infiltration. Note the convex, expanded border of the posterior vertebral body versus the normal posterior concavity of the adjacent vertebral bodies.

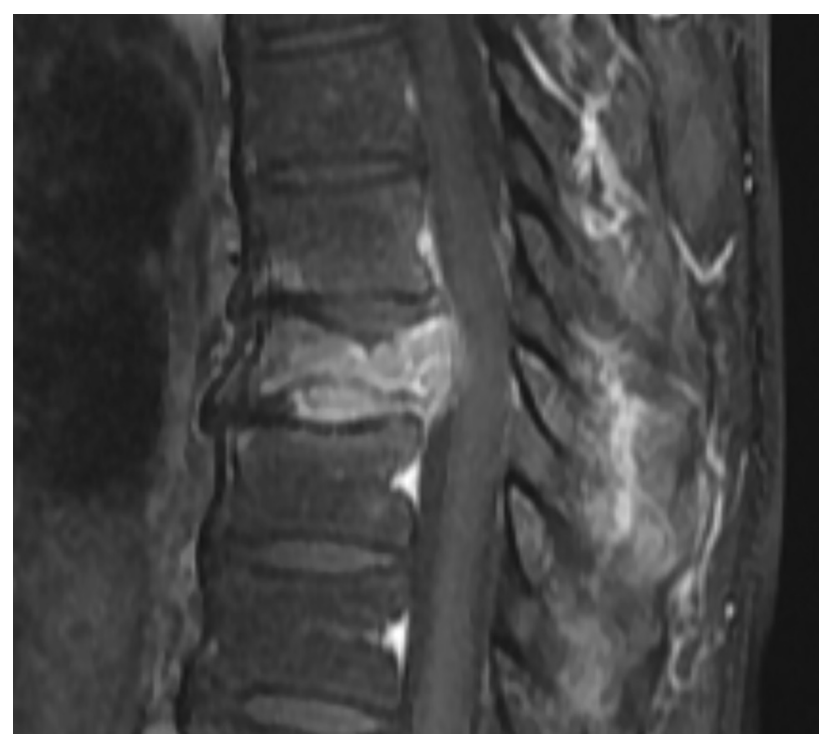

FIG 5. Increased enhancement in malignant VCF. Sagittal TIWI postgadolinium with fat saturation of the lumbar spine demonstrates an enhancing malignant VCF of L2. The enhancement is greater than that of the normal adjacent vertebral bodies. Also demonstrated is an expanded posterior convex border.

tected on CT (see subsequent "CT" section). The fluid sign has proved to be a strong indicator of benign VCFs in prediction models, though rarely it can develop in malignant VCFs., 18,19,26

Use of postgadolinium T1WI, ideally with fat suppression, may also yield beneficial information. ${ }^{11-13,15,16}$ As described above, findings in the epidural and paravertebral spaces on postcontrast MR imaging can help discriminate benign and malignant VCFs. In addition, the pattern and degree of intraosseous enhancement relative to normal adjacent vertebrae or noncontrast T1WI help to distinguish benign from malignant VCFs. Heterogeneous and relatively increased enhancement tends to be an in- dicator of malignancy (Fig 5). ${ }^{12,13,15}$ Typically benign fractures will have enhancement that is equivalent to adjacent normal vertebrae, the so-called "return to normal signal intensity," with additional horizontal bands of high or low SI parallel to the fractured endplate. ${ }^{12,13,15}$ In certain cases, an initial MR imaging, even with contrast, can be equivocal or can suggest malignancy even when clinical and other diagnostic tests do not indicate it. In equivocal cases, 1 option for problem solving is a follow-up gadolinium-enhanced MR imaging performed 2-3 months later. Benign VCFs will typically show a decrease or resolution of enhancement, while malignant VCFs will demonstrate persistent or progressive enhancement. ${ }^{28}$

Diffusion-Weighted Imaging. Application of DWI in relation to VCF evaluation is relatively new. As with its use intracranially, the technique is based on the ability to measure changes in the mobility of water molecules (Brownian motion) in various tissues. ${ }^{30}$ Diffusion is presumed to be increased in osteoporotic fractures due to bone marrow edema, which allows relatively unimpeded extracellular water molecule movement (Fig 9). With malignant VCF, diffusion is predicted to be restricted due to the typically high cellularity of tumor tissue (Fig 9). ${ }^{31}$ Restricted diffusion will appear as a hyperintensity, signifying tumor on DWI, with corresponding hypointensity on apparent coefficient images, whereas benign edema will be hypo- or isointense on DWI. ${ }^{31,32}$

DWI can also be quantitatively assessed. An ROI is selected within the vertebrae, and an ADC value is calculated. The ADC value is a measure of water molecule displacement per unit of time, with units of square millimeters/second. ${ }^{30}$ Multiple MR imaging sequences have been explored to maximize the distinction between the signal intensity and $\mathrm{ADC}$ values of benign and malignant VCFs, including steady-state precession, spin-echo, fast spinecho, echo-planar imaging, and single-shot fast spin-echo diffusionweighted techniques, as well as optimization of b-values. ${ }^{18,27,30,32-45}$ The results have been mixed because some of these studies can separate benign and malignant VCFs similar to conventional MR imaging, while others fail to find similar conclusions. Thus, it is unclear whether DWI provides an advantage over conventional MR imaging. ${ }^{27}$ One possible reason for conflicting results is the presence of intravertebral hematoma. One study evaluated patients with lowimpact trauma, high-impact trauma, and known metastatic VCFs. Those with high-impact trauma were found to have intermediate ADC values, similar to metastatic disease. ${ }^{46}$ DWI may provide beneficial information in combination with conventional imaging; recently, Sung et $\mathrm{al}^{42}$ have shown improved sensitivity, specificity, and accuracy when the 2 were used in conjunction.

Dynamic Contrast-Enhanced Imaging. Dynamic contrast-enhanced imaging is a technique in which contrast uptake is measured as changes in signal intensity across time. It allows qualitative and quantitative assessment of vascularity and hemodynamics, typically referred to as perfusion. Multiple perfusion parameters have been assessed, some of which included peak contrast percentage, enhancement slope, time-intensity curves, interstitial volume, plasma flow, plasma volume, permeability, wash-in slope, and area under the curve. The ability of perfusion parameters to differentiate benign and malignant VCFs is not convincingly different from that of conventional MR imaging. One early study was 


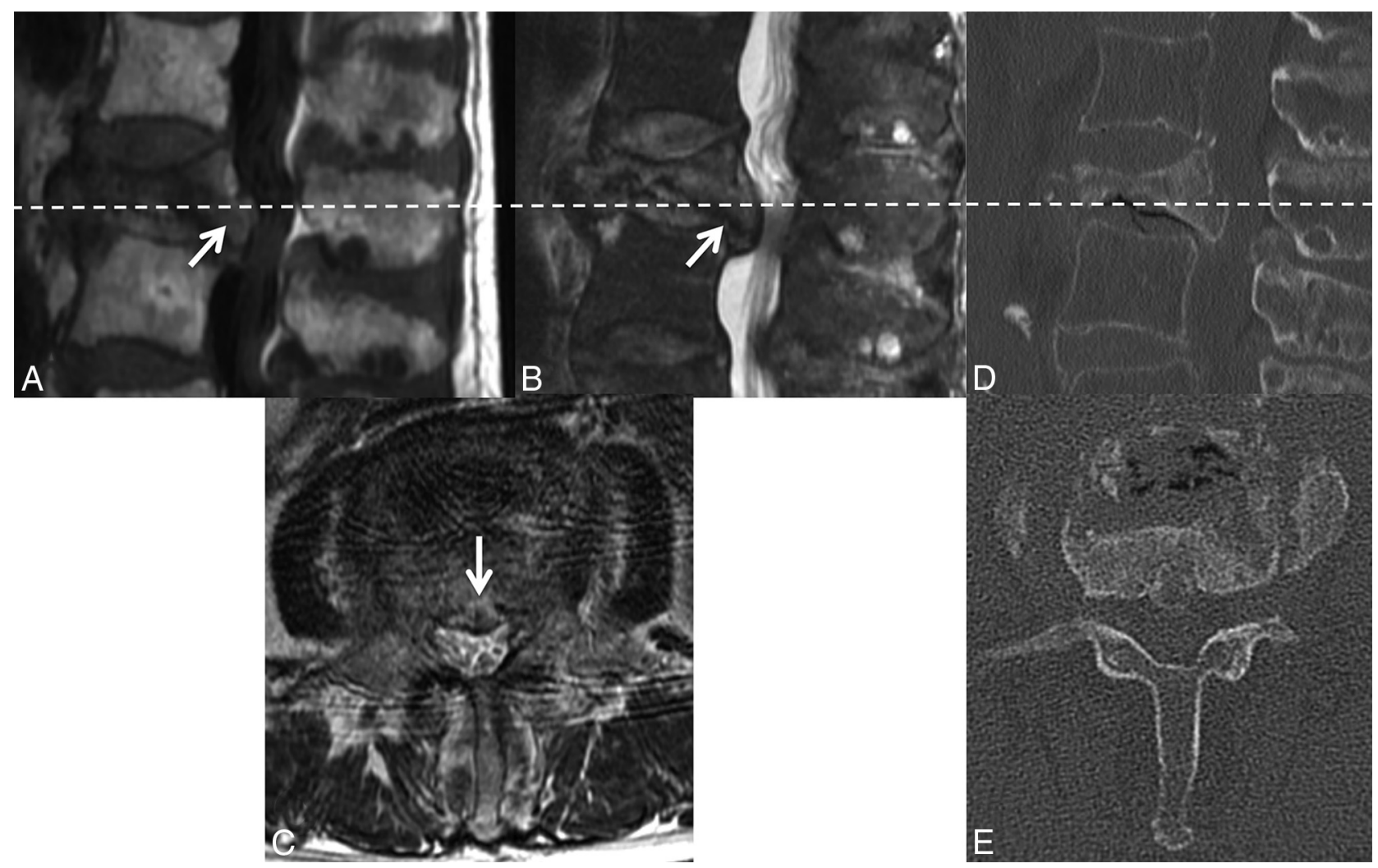

FIG 6. Retropulsion of a bone fragment in a benign VCF. Sagittal TIWI $(A)$ and T2WI (B) with fat saturation of the lumbar spine demonstrate a retropulsed bone fragment (arrow) compressing the thecal sac and narrowing the spinal canal in this benign VCF (C), best seen on the axial T2WI. A similar appearance is demonstrated on the axial $(D)$ and sagittal $(E)$ reformatted thoracic spine CT scans.

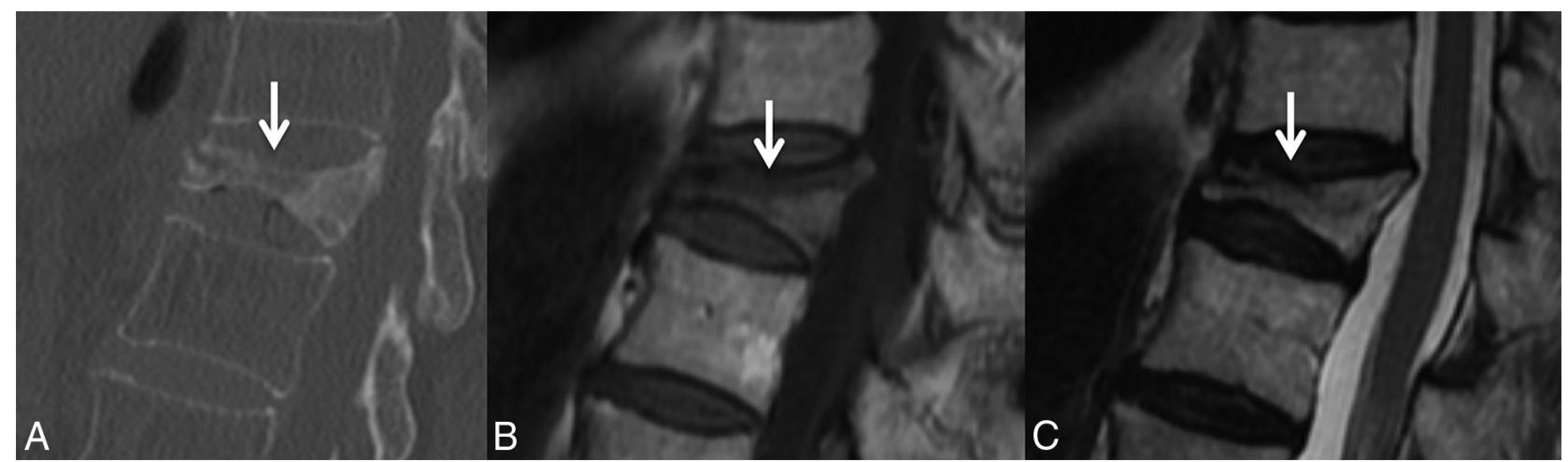

FIG 7. Linear horizontal fracture line in a benign VCF. As seen on the sagittal reformat from a thoracic spine CT in bone windows ( $A$ ), there is a lucent fracture line (arrow) paralleling the superior endplate of T11. On MR imaging, this fracture is seen as a linear horizontal line (arrow) of T1 and T2 hypointensity through the T11 vertebral body, TTWI (B) and T2WI (C).

unable to find perfusion differences, specifically in cases of acute osteoporotic VCFs. ${ }^{47}$ However, subsequent studies using more sophisticated analytic tools have been more successful in separating acute benign and malignant VCFs, though with slightly conflicting results based on the perfusion parameter assessed. ${ }^{48-50}$

Chemical Shift. In-phase and opposed-phase imaging is an additional MR imaging technique relatively recently being applied for the assessment of differentiating benign and malignant VCFs. With in-phase imaging, at $1.5 \mathrm{~T}$ and a TE of $4.6 \mathrm{~ms}$, both fat and water protons will contribute to the radiofrequency signal and increased SI. ${ }^{51}$ On opposed-phase imaging, at $1.5 \mathrm{~T}$ and a TE of $4.6 \mathrm{~ms}$, the fat dipole is opposite that of water and cancels the radiofrequency signal of water, resulting in lower net signal intensity. ${ }^{51}$ Normal red and yellow bone marrow has varying amounts of both fat and water components, which have loss of SI on opposed-phase imaging. ${ }^{52}$ In contrast, malignant spinal lesions infiltrate bone marrow causing no or only slight loss on opposed-phase imaging. ${ }^{52}$ The signal intensity ratio or the ratio of opposed-phase to in-phase SI is a measurement that, at values of $>0.8$, is a fairly sensitive and specific sign of malignancy. ${ }^{18,52}$ Ratios of $\geq 1.0$ are even more specific. ${ }^{53}$

\section{CT}

CT is a readily accessible technique that can be used to evaluate patients with back pain and suspected VCFs. Laredo et $\mathrm{al}^{54}$ were 
the earliest group to evaluate the diagnostic value of CT. They reported several CT features that were more frequently found in benign VCFs, with the following findings achieving statistical significance: fracture of the anterolateral or posterior cortex of the vertebral body, a retropulsed bone, fracture lines within cancellous bone, and a diffuse thin paraspinal soft-tissue thickening.

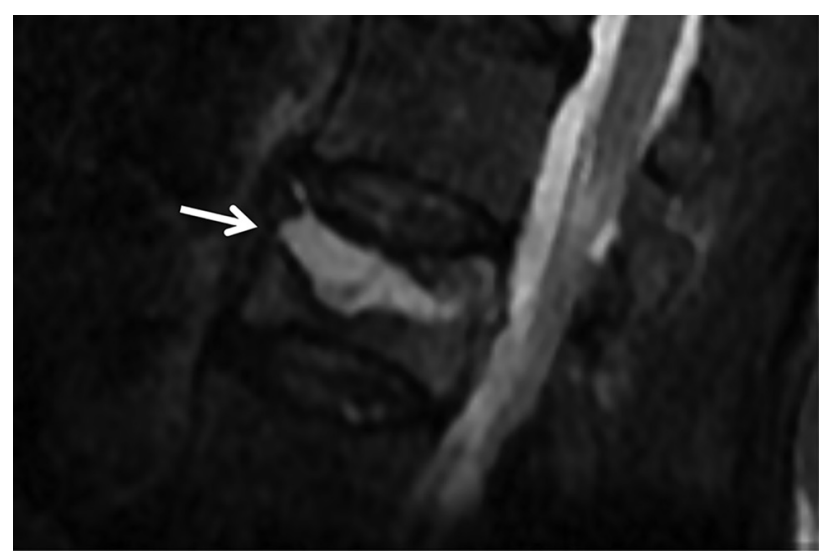

FIG 8. Fluid cleft in a benign VCF. Sagittal T2WI with fat saturation of the lumbar spine demonstrates a triangular fluid cleft (arrow) seen within this benign VCF.
The "puzzle sign" is a descriptive term of the presence of sharp fracture lines without cortical destruction so that the displaced bone fragments could be reconstructed into their original position to complete the "puzzle" (Fig 2). In addition, although uncommon and not reaching statistical significance, an intravertebral vacuum phenomenon (air-filled cleft) was never visualized in malignant fractures.

CT findings predictive of malignant VCFs revolve around destruction and the presence of masses. Any form of destruction whether of cortical bone, cancellous bone, or the pedicle was predictive of malignant VCF. As with MR imaging, an epidural or focal paravertebral soft-tissue mass also favors a malignant VCF. ${ }^{54,55}$

The use of various scoring systems and prediction models can be a helpful strategy for delineating benign from malignant VCFs. ${ }^{10,19,56}$ Yuzawa et $\mathrm{al}^{10}$ found that the combination of CT characteristics and MR imaging features enhanced the accuracy of differentiating benign from malignant fractures. The CT findings used in this scoring system included sharp fracture lines without osteolytic destruction in benign VCFs and osteolytic destruction in malignant VCFs. While MR imaging is typically superior in the depiction of most spine pathology, such studies exemplify the

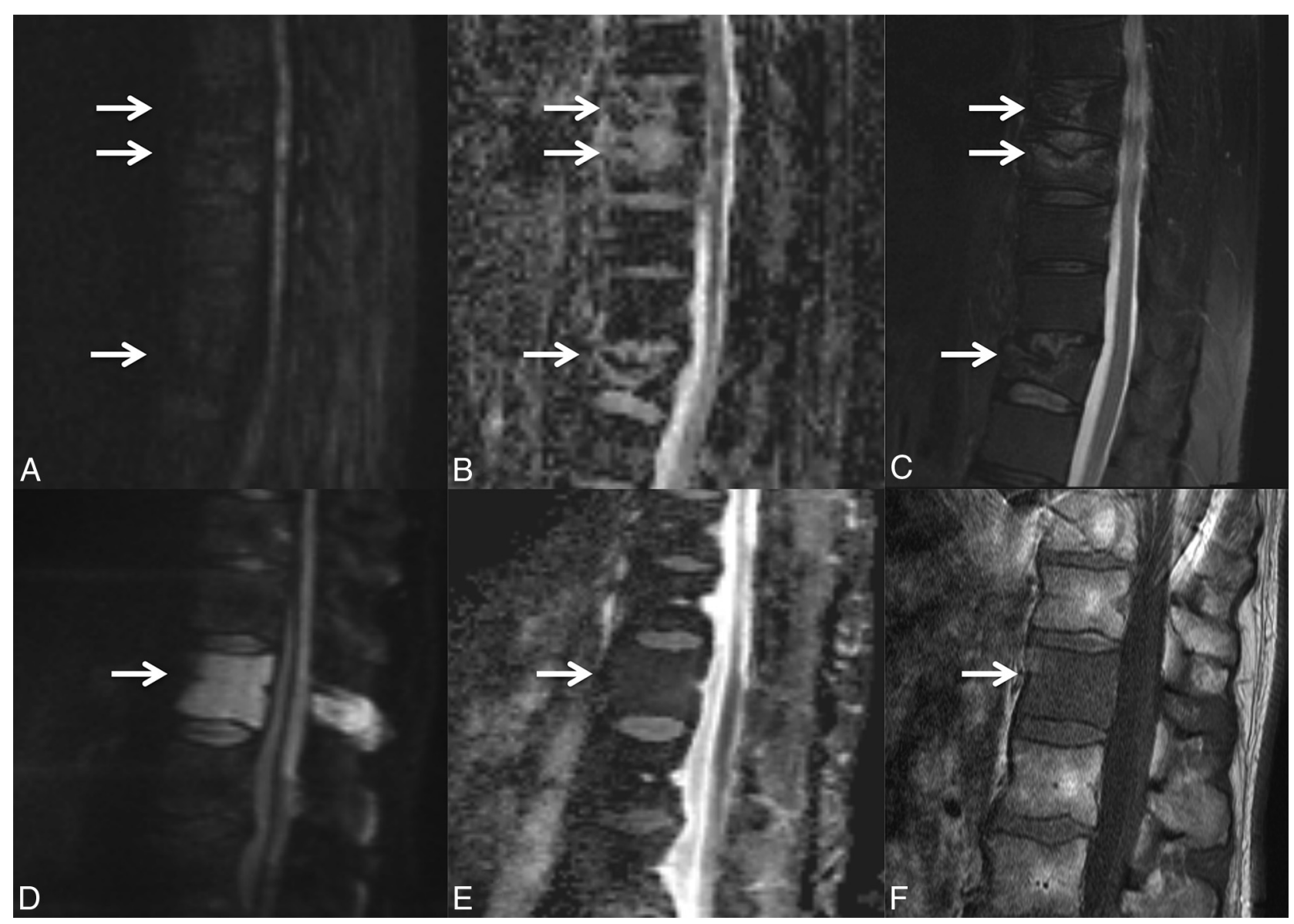

FIG 9. DWI of benign and malignant VCFs. Multiple benign osteoporotic VCFs (A-C, arrows) are seen in the lower thoracic spine. Sagittal DWI $(A)$ and the corresponding ADC map $(B)$ demonstrate the absence of diffusion restriction. Sagittal fat-saturated T2WI $(C)$ demonstrates T2 hyperintensity about the fracture lines compatible with edema from an acute/subacute fracture. In contrast, malignant lymphomatous involvement of T12 (D-F, arrow) demonstrates diffuse diffusion restriction $(D)$ with corresponding low ADC values $(E)$. On the sagittal TTWI $(F)$, there is slight loss of height of the superior and inferior endplates and diffuse $\mathrm{T} 1$ hypointensity compatible with marrow replacement. 


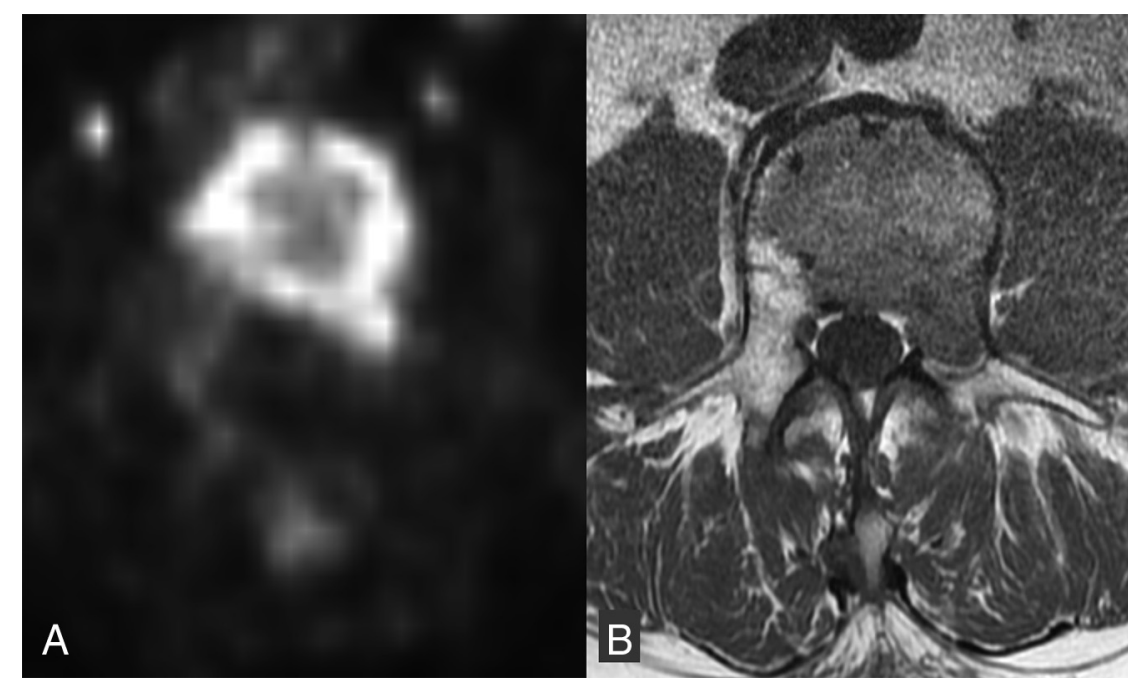

FIG 10. FDG avid malignant VCF. Axial non-attenuation-corrected PET $(A)$ at the level of the malignant lumbar VCF with increased FDG activity throughout the vertebral body and into the left pedicle. Corresponding axial TTWI $(B)$ shows the area of low T1 signal tumor infiltration throughout the vertebral body and left pedicle.

utility of CT in providing excellent characterization of cortical and cancellous bone and fracture margins.

\section{FDG-PET/CT}

While MR imaging and CT are widely used in the assessment of VCFs, they provide primarily anatomic information and occasionally do not yield a definitive diagnosis. In addition, MR imaging may not be an option in patients unable to undergo it due to implanted devices or other limitations. FDG-PET/CT may have an adjunctive role in differentiating benign and malignant VCFs by providing metabolic information. ${ }^{57-60}$ It has been shown that there is overlap in the appearance of benign and malignant bone lesions on this technique, but to date, published data are not extensive. $^{57,58}$

Generally, fractures due to tumors are expected to accumulate FDG, while benign fractures are not expected to accumulate FDG to a similarly high degree. The maximum standard uptake value (SUV) on PET of malignant pathologic fractures of various bones (pelvis, long bones, spine, and rib) is significantly higher compared with benign fractures. ${ }^{58}$ When evaluating vertebrae specifically, the SUV is significantly higher in malignant than in benign compression fractures (Fig 10). ${ }^{57,59}$ Most of these studies used a threshold SUV to classify the lesions, while some incorporated comparison with liver SUV. The cutoff SUVs ranged from 3 to 4.7. Alternative criteria included 2 SDs above (malignant) or below (benign) the liver SUV or direct comparison with the SUV of the liver in indeterminate (SUV 2-3) lesions.

However, there are limitations to FDG-PET. Case reports have shown benign fractures with much higher-than-expected SUVs, even up to 9.3 in an acute pelvic fracture. ${ }^{61}$ As such cases demonstrate, acute fractures can be a source of false-positive findings. FDG uptake was noted to be most intense in the acute phase of a benign fracture and returned to normal by approximately 3 months. ${ }^{5,62}$ Failure of a fracture to return to a normal FDG uptake by 3 months may indicate malignancy or osteomyelitis. ${ }^{5}$ An additional limitation is that patients receiving bone marrow-stimu- lating agents may have falsely elevated maximum SUVs related to increased bone marrow metabolism, so this factor should be considered in the interpretation of FDG uptake. ${ }^{57}$ In summary, the precise role of FDG PET in imaging of benign and malignant VCFs has yet to be defined. It may provide the most benefit when CT or MR imaging findings are indeterminate and the exact age of the fracture is known.

\section{SPECT}

Bone scintigraphy has long been used for the evaluation of intraosseous lesions in patients with known malignancy and back pain. In clinical practice, abnormal uptake within $\geq 1$ vertebrae is seen relatively commonly, especially in the elderly who have a high rate of benign disease that can cause uptake. SPECT has the advantage over planar imaging of offering exact localization of vertebral lesions. Because MR imaging is sometimes not feasible due to implantable devices, claustrophobia, or length of the study, a single study evaluated whether SPECT could be used as a substitute for MR imaging to distinguish benign from malignant VCFs. ${ }^{63}$ Imaging features signifying malignancy included the following: vertebral body + pedicle uptake, vertebral body + pedicle + spinous process uptake, and marginal uptake in a cold lesion. Lesions were classified as benign if they had uptake in the vertebral body + facet joint or just in the facet joint. SPECT was found to be comparable with MR imaging with similar sensitivity and specificity for differentiating benign and malignant VCFs, though there was significantly lower accuracy. In cases in which there was complete replacement of normal fatty marrow on MR imaging, no significant differences in sensitivity, specificity, or accuracy between SPECT and MR imaging were seen, suggesting that SPECT may be most useful in this subset of patients. ${ }^{63}$

\section{CONCLUSIONS}

Advanced imaging plays a crucial role in distinguishing benign from malignant VCFs. The various modalities each have unique attributes. CT provides excellent information about the osseous integrity and fracture margins. PET-CT and SPECT have relatively sparse supporting literature, though with comparable diagnostic results to CT and MR imaging. MR imaging is the established technique of choice, with strong evidence for multiple distinguishing imaging features, which can allow relatively confident characterization of the nature of a VCF. Features strongly predictive of malignancy include expansion of the fractured vertebral body, an epidural and/or paraspinal soft tissue mass, and discrete lesions within the bone, especially if destructive. Features strongly predictive of benignity include lack of these malignant features and at least partial preservation of normal marrow signal, visible fluid- and/or air-filled fracture lines/clefts, and retropulsion of the cortex (Table). 


\section{ACKNOWLEDGMENTS}

The authors acknowledge the assistance of Sonia Watson, $\mathrm{PhD}$, in editing and submission of the manuscript.

\section{REFERENCES}

1. Melton LJ 3rd. Epidemiology of spinal osteoporosis. Spine (Phila Pa 1976) 1997;22:2S-11S CrossRef Medline

2. Coleman RE. Skeletal complications of malignancy. Cancer 1997;80: 1588-94 Medline

3. Porter BA, Shields AF, Olson DO. Magnetic resonance imaging of bone marrow disorders. Radiol Clin North Am 1986;24:269-89 Medline

4. Yamato M, Nishimura G, Kuramochi E, et al. MR appearance at different ages of osteoporotic compression fractures of the vertebrae. Radiat Med 1998;16:329-34 Medline

5. Zhuang H, Sam JW, Chacko TK, et al. Rapid normalization of osseous FDG uptake following traumatic or surgical fractures. Eur J Nucl Med Mol Imaging 2003;30:1096-103 CrossRef Medline

6. Lecouvet FE, Malghem J, Michaux L, et al. Vertebral compression fractures in multiple myeloma, Part II: assessment of fracture risk with MR imaging of spinal bone marrow. Radiology 1997;204: 201-05 CrossRef Medline

7. Lecouvet FE, Vande Berg BC, Maldague BE, et al. Vertebral compression fractures in multiple myeloma, Part I: distribution and appearance at MR imaging. Radiology 1997;204:195-99 CrossRef Medline

8. Layton KF, Thielen KR, Cloft HJ, et al. Acute vertebral compression fractures in patients with multiple myeloma: evaluation of vertebral body edema patterns on MR imaging and the implications for vertebroplasty. AJNR Am J Neuroradiol 2006;27:1732-34 Medline

9. Abdel-Wanis ME, Solyman MT, Hasan NM. Sensitivity, specificity and accuracy of magnetic resonance imaging for differentiating vertebral compression fractures caused by malignancy, osteoporosis, and infections. J Orthop Surg (Hong Kong) 2011;19: 145-50 CrossRef Medline

10. Yuzawa Y, Ebara S, Kamimura M, et al. Magnetic resonance and computed tomography-based scoring system for the differential diagnosis of vertebral fractures caused by osteoporosis and malignant tumors. J Orthop Sci 2005;10:345-52 CrossRef Medline

11. Moulopoulos LA, Yoshimitsu K, Johnston DA, et al. MR prediction of benign and malignant vertebral compression fractures. J Magn Reson Imaging 1996;6:667-74 CrossRef Medline

12. Cuénod CA, Laredo JD, Chevret S, et al. Acute vertebral collapse due to osteoporosis or malignancy: appearance on unenhanced and gadolinium-enhanced MR images. Radiology 1996; 199:541-49 CrossRef Medline

13. Shih TT, Huang KM, Li YW. Solitary vertebral collapse: distinction between benign and malignant causes using MR patterns. J Magn Reson Imaging 1999;9:635-42 Medline

14. Jung HS, Jee WH, McCauley TR, et al. Discrimination of metastatic from acute osteoporotic compression spinal fractures with MR imaging. Radiographics 2003;23:179-87 CrossRef Medline

15. Rupp RE, Ebraheim NA, Coombs RJ. Magnetic resonance imaging differentiation of compression spine fractures or vertebral lesions caused by osteoporosis or tumor. Spine (Phila Pa 1976) 1995;20: 2499-503; discussion 2504 CrossRef Medline

16. Tan DY, Tsou IY, Chee TS. Differentiation of malignant vertebral collapse from osteoporotic and other benign causes using magnetic resonance imaging. Ann Acad Med Singapore 2002;31:8-14 Medline

17. Yuh WT, Zachar CK, Barloon TJ, et al. Vertebral compression fractures: distinction between benign and malignant causes with MR imaging. Radiology 1989;172:215-18 CrossRef Medline

18. Thawait SK, Marcus MA, Morrison WB, et al. Research synthesis: what is the diagnostic performance of magnetic resonance imaging to discriminate benign from malignant vertebral compression fractures? Systematic review and meta-analysis. Spine (Phila Pa 1976) 2012;37:E736-44 CrossRef Medline
19. Thawait SK, Kim J, Klufas RA, et al. Comparison of four prediction models to discriminate benign from malignant vertebral compression fractures according to MRI feature analysis. AJR Am J Roentgenol 2013;200:493-502 CrossRef Medline

20. Kaplan PA, Orton DF, Asleson RJ. Osteoporosis with vertebral compression fractures, retropulsed fragments, and neurologic compromise. Radiology 1987;165:533-35 CrossRef Medline

21. Ishiyama M, Fuwa S, Numaguchi Y, et al. Pedicle involvement on MR imaging is common in osteoporotic compression fractures. AJNR Am J Neuroradiol 2010;31:668-73 CrossRef Medline

22. Lehman VT, Wood CP, Hunt $\mathrm{CH}$, et al. Facet joint signal change on MRI at levels of acute/subacute lumbar compression fractures. AJNR Am J Neuroradiol 2013;34:1468-73 CrossRef Medline

23. Kim DH, Rosenblum JK, Panghaal VS, et al. Differentiating neoplastic from nonneoplastic processes in the anterior extradural space. Radiology 2011;260:825-30 CrossRef Medline

24. Baker LL, Goodman SB, Perkash I, et al. Benign versus pathologic compression fractures of vertebral bodies: assessment with conventional spin-echo, chemical-shift, and STIR MR imaging. Radiology 1990;174:495-502 CrossRef Medline

25. Dammers R, Bijvoet HW, Driesse MJ, et al. Occurrence of malignant vertebral fractures in an emergency room setting. Emerg Med J 2007; 24:707-09 CrossRef Medline

26. Baur A, Stäbler A, Arbogast S, et al. Acute osteoporotic and neoplastic vertebral compression fractures: fluid sign at MR imaging. $R a-$ diology 2002;225:730-35 CrossRef Medline

27. Castillo M, Arbelaez A, Smith JK, et al. Diffusion-weighted MR imaging offers no advantage over routine noncontrast $M R$ imaging in the detection of vertebral metastases. AJNR Am J Neuroradiol 2000; 21:948-53 Medline

28. An HS, Andreshak TG, Nguyen C, et al. Can we distinguish between benign versus malignant compression fractures of the spine by magnetic resonance imaging? Spine (Phila $\mathrm{Pa}$ 1976) 1995;20:1776-82 CrossRef Medline

29. Ishiyama M, Numaguchi $Y$, Makidono A, et al. Contrast-enhanced MRI for detecting intravertebral cleft formation: relation to the time since onset of vertebral fracture. AJR Am J Roentgenol 2013;201: W117-23 CrossRef Medline

30. Raya JG, Dietrich O, Reiser MF, et al. Methods and applications of diffusion imaging of vertebral bone marrow. J Magn Reson Imaging 2006;24:1207-20 CrossRef Medline

31. Baur A, Stabler A, Huber A, et al. Diffusion-weighted magnetic resonance imaging of spinal bone marrow. Semin Musculoskelet Radiol 2001;5:35-42 CrossRef Medline

32. Baur A, Stäbler A, Brüning R, et al. Diffusion-weighted MR imaging of bone marrow: differentiation of benign versus pathologic compression fractures. Radiology 1998;207:349-56 CrossRef Medline

33. Zhou XJ, Leeds NE, McKinnon GC, et al. Characterization of benign and metastatic vertebral compression fractures with quantitative diffusion MR imaging. AJNR Am J Neuroradiol 2002;23:165-70 Medline

34. Tang G, Liu Y, Li W, et al. Optimization of $\mathbf{b}$ value in diffusionweighted MRI for the differential diagnosis of benign and malignant vertebral fractures. Skeletal Radiol 2007;36:1035-41 CrossRef Medline

35. Baur A, Huber A, Ertl-Wagner B, et al. Diagnostic value of increased diffusion weighting of a steady-state free precession sequence for differentiating acute benign osteoporotic fractures from pathologic vertebral compression fractures. AJNR Am J Neuroradiol 2001; 22:366-72 Medline

36. Baur-Melnyk A. Malignant versus benign vertebral collapse: are new imaging techniques useful? Cancer Imaging 2009;9 Spec No A:S49-51 CrossRef Medline

37. Karchevsky M, Babb JS, Schweitzer ME. Can diffusion-weighted imaging be used to differentiate benign from pathologic fractures? A meta-analysis. Skeletal Radiol 2008;37:791-95 CrossRef Medline

38. Park SW, Lee JH, Ehara S, et al. Single shot fast spin echo diffusionweighted MR imaging of the spine; is it useful in differentiating 
malignant metastatic tumor infiltration from benign fracture edema? Clin Imaging 2004;28:102-08 CrossRef Medline

39. Biffar A, Baur-Melnyk A, Schmidt GP, et al. Quantitative analysis of the diffusion-weighted steady-state free precession signal in vertebral bone marrow lesions. Invest Radiol 2011;46:601-09 CrossRef Medline

40. Mubarak F, Akhtar W. Acute vertebral compression fracture: differentiation of malignant and benign causes by diffusion weighted magnetic resonance imaging. J Pak Med Assoc 2011;61:555-58 Medline

41. Wonglaksanapimon S, Chawalparit O, Khumpunnip S, et al. Vertebral body compression fracture: discriminating benign from malignant causes by diffusion-weighted MR imaging and apparent diffusion coefficient value. J Med Assoc Thai 2012;95:81-87 Medline

42. Sung JK, Jee WH, Jung JY, et al. Differentiation of acute osteoporotic and malignant compression fractures of the spine: use of additive qualitative and quantitative axial diffusion-weighted MR imaging to conventional MR imaging at 3.0 T. Radiology 2014;271:488-98 CrossRef Medline

43. Park HJ, Lee SY, Rho MH, et al. Single-shot echo-planar diffusionweighted MR imaging at $3 \mathrm{~T}$ and $1.5 \mathrm{~T}$ for differentiation of benign vertebral fracture edema and tumor infiltration. Korean J Radiol 2016;17:590-97 CrossRef Medline

44. Luo Z, Litao L, Gu S, et al. Standard-b-value vs low-b-value DWI for differentiation of benign and malignant vertebral fractures: a metaanalysis. Br J Radiol 2016;89:20150384 CrossRef Medline

45. Dietrich O, Geith T, Reiser MF, et al. Diffusion imaging of the vertebral bone marrow. NMR Biomed 2017;30 CrossRef Medline

46. Rumpel $\mathrm{H}$, Chong $\mathrm{Y}$, Porter DA, et al. Benign versus metastatic vertebral compression fractures: combined diffusion-weighted MRI and MR spectroscopy aids differentiation. Eur Radiol 2013;23: 541-50 CrossRef Medline

47. Chen WT, Shih TT, Chen RC, et al. Blood perfusion of vertebral lesions evaluated with gadolinium-enhanced dynamic MRI: in comparison with compression fracture and metastasis. J Magn Reson Imaging 2002;15:308-14 CrossRef Medline

48. Arevalo-Perez J, Peck KK, Lyo JK, et al. Differentiating benign from malignant vertebral fractures using T1-weighted dynamic contrast-enhanced MRI. J Magn Reson Imaging 2015;42:1039-47 CrossRef Medline

49. Geith T, Biffar A, Schmidt G, et al. Quantitative analysis of acute benign and malignant vertebral body fractures using dynamic contrast-enhanced MRI. AJR Am J Roentgenol 2013;200:W635-43 CrossRef Medline

50. Tokuda $\mathrm{O}$, Hayashi $\mathrm{N}$, Taguchi $\mathrm{K}$, et al. Dynamic contrast-enhanced perfusion MR imaging of diseased vertebrae: analysis of three parameters and the distribution of the time-intensity curve patterns. Skeletal Radiol 2005;34:632-38 CrossRef Medline
51. Erly WK, Oh ES, Outwater EK. The utility of in-phase/opposedphase imaging in differentiating malignancy from acute benign compression fractures of the spine. AJNR Am J Neuroradiol 2006;27: 1183-88 Medline

52. Zajick DC Jr, Morrison WB, Schweitzer ME, et al. Benign and malignant processes: normal values and differentiation with chemical shift MR imaging in vertebral marrow. Radiology 2005;237:590-96 CrossRef Medline

53. Ogura A, Hayakawa K, Maeda F, et al. Differential diagnosis of vertebral compression fracture using in-phase/opposed-phase and short TI inversion recovery imaging. Acta Radiol 2012;53:450-55 CrossRef Medline

54. Laredo JD, Lakhdari K, Bellaïche L, et al. Acute vertebral collapse: CT findings in benign and malignant nontraumatic cases. Radiology 1995;194:41-48 CrossRef Medline

55. Kubota T, Yamada K, Ito H, et al. High-resolution imaging of the spine using multidetector-row computed tomography: differentiation between benign and malignant vertebral compression fractures. J Comput Assist Tomogr 2005;29:712-19 CrossRef Medline

56. Wang KC, Jeanmenne A, Weber GM, et al. An online evidence-based decision support system for distinguishing benign from malignant vertebral compression fractures by magnetic resonance imaging feature analysis. J Digit Imaging 2011;24:507-15 CrossRef Medline

57. Bredella MA, Essary B, Torriani M, et al. Use of FDG-PET in differentiating benign from malignant compression fractures. Skeletal Radiol 2008;37:405-13 CrossRef Medline

58. Shin DS, Shon OJ, Byun SJ, et al. Differentiation between malignant and benign pathologic fractures with F-18-fluoro-2-deoxy-D-glucose positron emission tomography/computed tomography. Skeletal Radiol 2008;37:415-21 CrossRef Medline

59. Cho WI, Chang UK. Comparison of MR imaging and FDG-PET/CT in the differential diagnosis of benign and malignant vertebral compression fractures. J Neurosurg Spine 2011;14:177-83 CrossRef Medline

60. Aggarwal A, Salunke P, Shekhar BR, et al. The role of magnetic resonance imaging and positron emission tomography-computed tomography combined in differentiating benign from malignant lesions contributing to vertebral compression fractures. Surg Neurol Int 2013;4:S323-26 CrossRef Medline

61. Ravenel JG, Gordon LL, Pope TL, et al. FDG-PET uptake in occult acute pelvic fracture. Skeletal Radiol 2004;33:99-101 CrossRef Medline

62. Shon IH, Fogelman I. F-18 FDG positron emission tomography and benign fractures. Clin Nucl Med 2003;28:171-75 CrossRef Medline

63. Tokuda $\mathrm{O}$, Harada $\mathrm{Y}$, Ueda $\mathrm{T}$, et al. Malignant versus benign vertebral compression fractures: can we use bone SPECT as a substitute for MR imaging? Nucl Med Commun 2011;32:192-98 CrossRef Medline 